Supporting Information for

\title{
High-contrast dynamic reflecting system based on pneumatic micro/nanoscale surface morphing
}

Yang Shen, ${ }^{\dagger}$ Qiushun Zou ${ }^{\dagger}$, Bo $\mathrm{Wan}^{\dagger}$, Xiaoyi She ${ }^{\dagger}$, Runzhi You ${ }^{\dagger}$, Yi Luo $^{\dagger}$, Chongjun

$$
\operatorname{Jin}^{*} \dagger
$$

${ }^{\dagger}$ State Key Laboratory of Optoelectronic Materials and Technologies, School of Materials Science and Engineering, Sun Yat-sen University, Guangzhou 510275, China. "Corresponding author should be addressed: jinchjun@ mail.sysu.edu.cn

\section{Fabrication on pneumatic dynamic optical reflecting system}

(a)

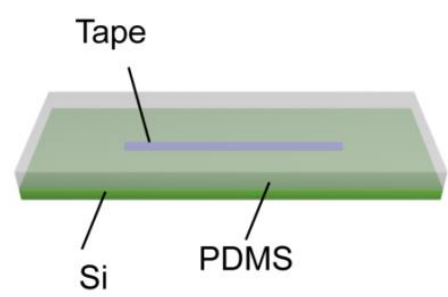

(d)

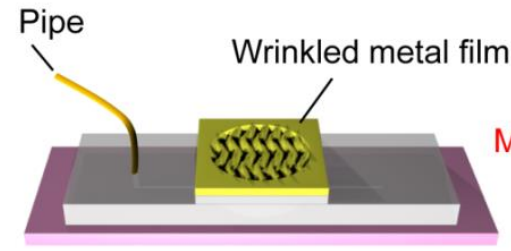

(b) Inlet Central hole

PDMS molding
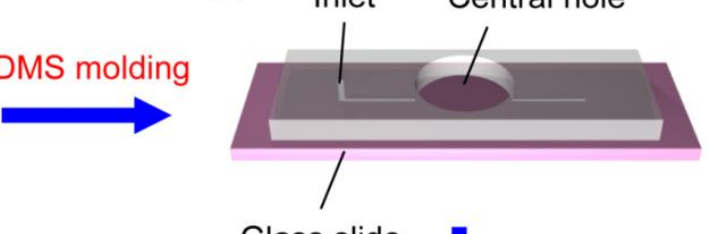

Bonding

(c)

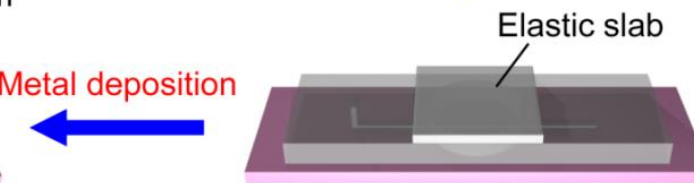

Figure S1. Fabrication procedure of a pneumatic dynamic optical reflecting system. (a) PDMS molding. (b) Bonding the PDMS microfluidic slab to a glass slide 
through oxygen plasma treatment. (c) Sealing the opening by an elastic slab through oxygen plasma treatment. (d) Metal deposition.

2. Simulated stress distribution of an Ag film/VHB 4910 elastomer bilayer under pneumatic inflation

(a)

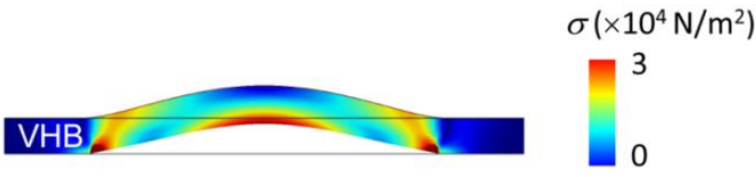

(b)

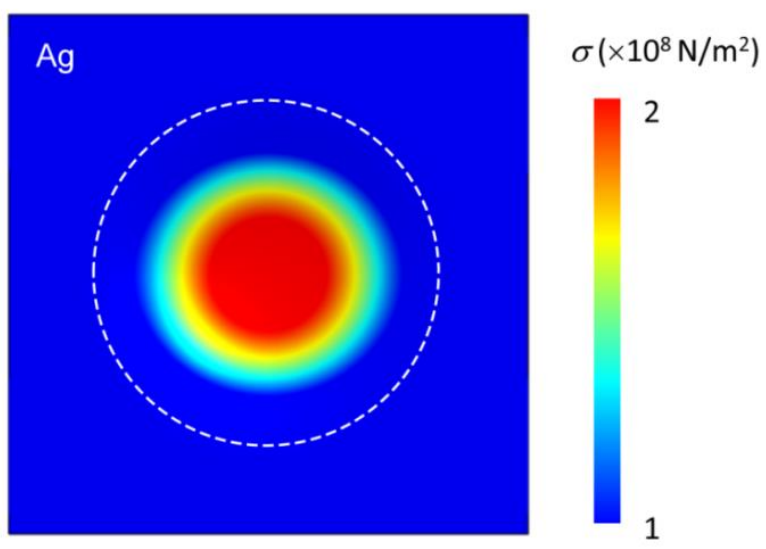

Figure S2. Simulated stress distribution of an Ag film/VHB 4910 elastomer bilayer under pneumatic inflation of $\mathbf{4} \mathbf{k P a}$. (a) Cross-section-view. (b) Top-view. The white dashed circle indicates a loading area for pressurization. 
3. Simulated wavelengths of the surface wrinkles under a set of gas pressure loadings.

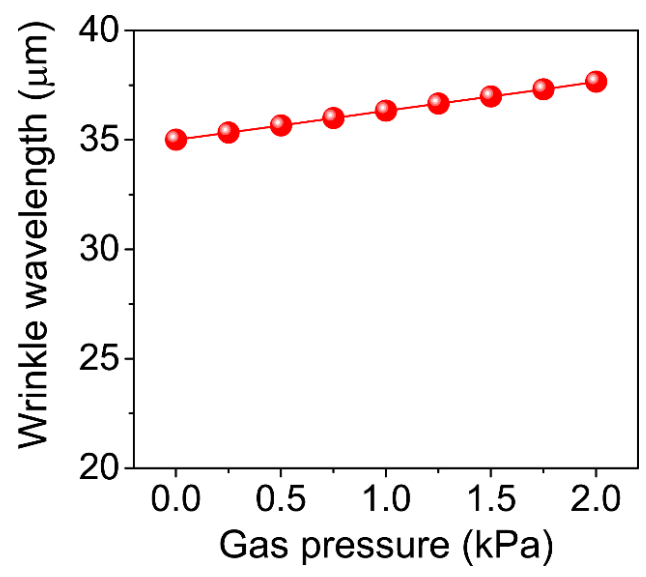

Figure S3. Simulated wavelengths of the surface wrinkles under a set of gas pressure loadings from 0 to $2 \mathrm{kPa}$ for an $\mathrm{Ag} / \mathrm{VHB} 4910$ elastomer bilayer.

4. AFM measurements of three samples with different substrates.

(a)

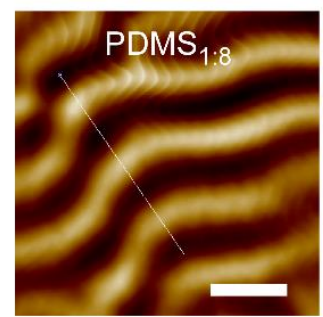

(d)

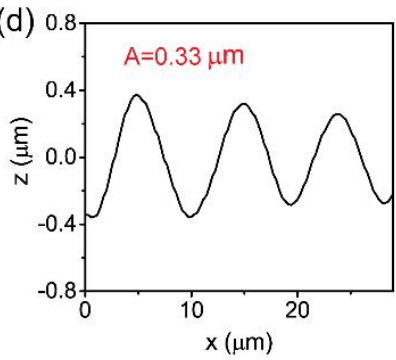

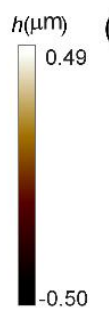

(b)
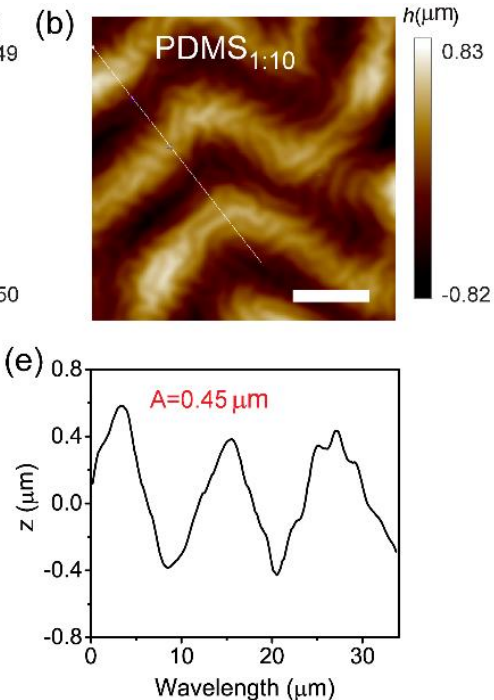

(c)

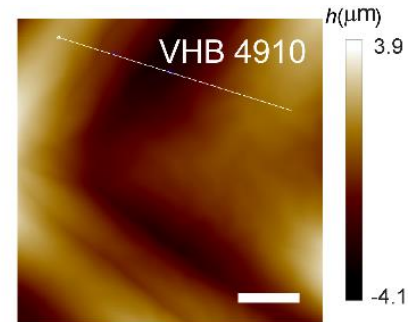

(f)

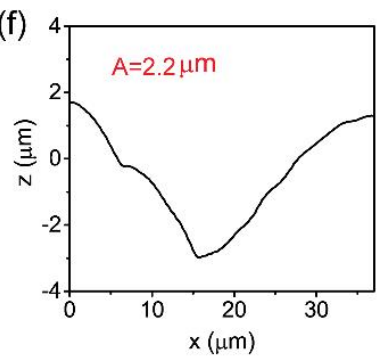

Figure S4. AFM measurements of three samples with different substrates. (a) PDMS $_{1: 8 .}$ (b) PDMS 1:10. (c) VHB 4910. Scale bars, $10 \mu \mathrm{m}$. 
5. Degree of reshaping for the wrinkles with different wavelengths under the same change of amplitude.

(a) small wrinkle

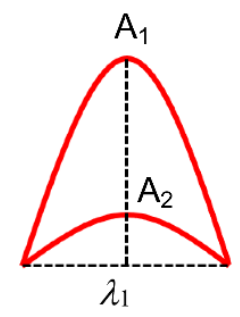

(b) large wrinkle

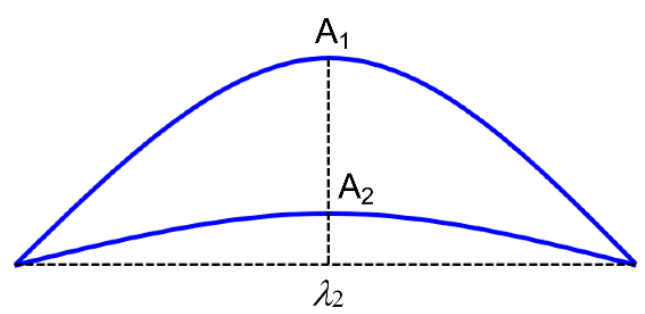

Figure S5. Degree of reshaping for the wrinkles with different wavelengths under the same change of amplitude. (a) small wrinkle; (b) large wrinkle. For a wrinkle with a smaller wavelength, it can reshape itself more significantly under the same change of amplitude, compared to the larger one. 


\section{Hysteresis and morphological evolution of an Ag film/VHB 4910 elastomer}

bilayer during a pneumatic cycle.

(a)

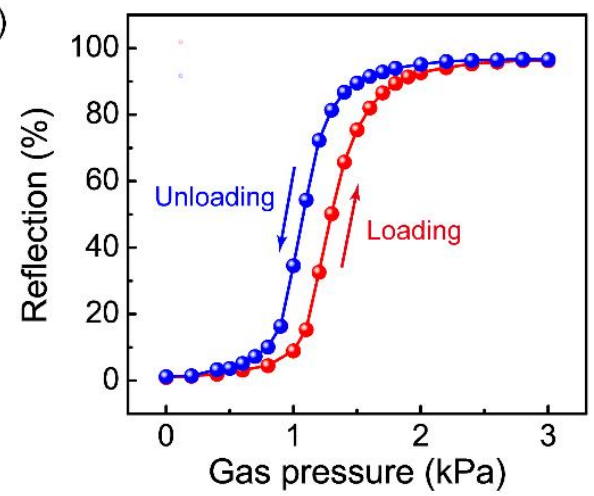

(b)

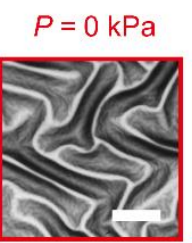

$0.5 \mathrm{kPa}$

$1.0 \mathrm{kPa}$

$1.5 \mathrm{kPa}$

$2.0 \mathrm{kPa}$

$3.0 \mathrm{kPa}$

$4.0 \mathrm{kPa}$
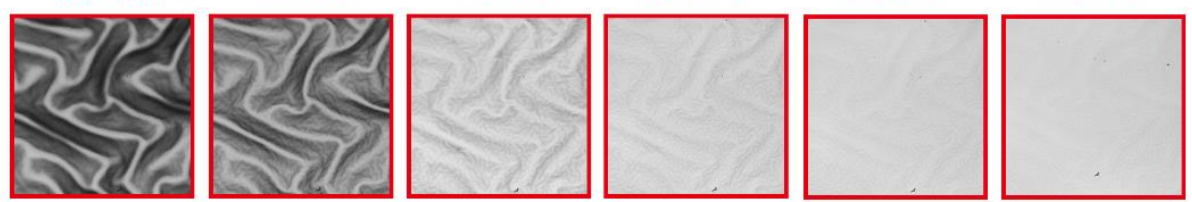

(c)
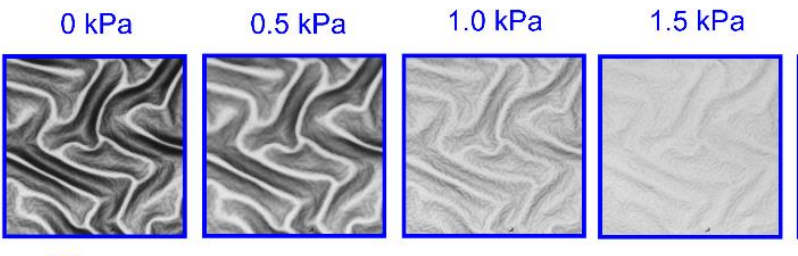

$2.0 \mathrm{kPa}$

$3.0 \mathrm{kPa}$

$P=4.0 \mathrm{kPa}$

Figure S6. Hysteresis and morphological evolution of a Ag film/VHB 4910 elastomer bilayer during a pneumatic cycle. (a) Reflection-pressure hysteresis loop under loading and unloading. The degree of hysteresis (DH) is $14 \%$. DH is defined as $\mathrm{DH}(\%)=\frac{A_{\text {unloading }}-A_{\text {loading }}}{A_{\text {loading }}} \times 100 \%$, where $A_{\text {unloading }}$ and $A_{\text {loading }}$ are the areas of the curves under loading and unloading, respectively. (b) Microscopic images showing the morphological evolution of the Ag film as pressure was increased from 0 to $4 \mathrm{kPa}$. (c) Microscopic images showing the morphological evolution of the Ag film as pressure was decreased from 4 to $0 \mathrm{kPa}$. Scale bar, $50 \mu \mathrm{m}$. 
7. Effect of Young's Moduli on the wavelengths of surface wrinkles for three types of elastic substrates.

(a) Ag film/VHB 4910

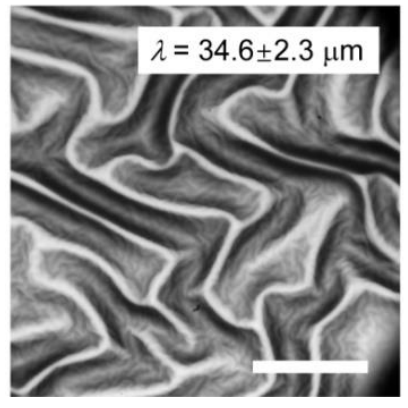

(b) Ag film/PDMS $1: 10$

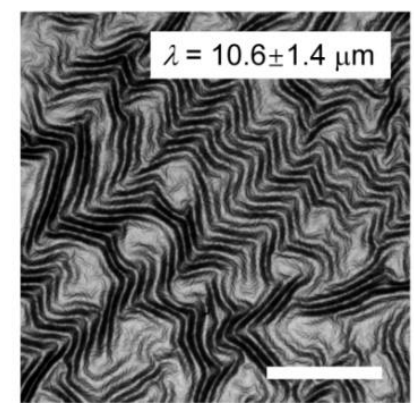

(c) $\quad$ Ag film/PDMS $1: 8$

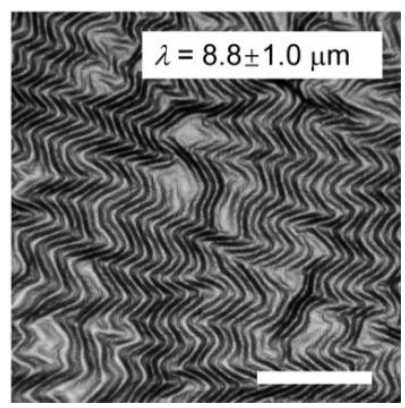

Figure S7. Microscopic images showing the wrinkle surfaces of three sensors with different elastomers after unloading of the gas pressures. (a) Ag film/VHB 4910. (b) Ag film/PDMS $1: 10$. (c) Ag film/PDMS $1: 10$. All scale bars in the above figures are $100 \mu \mathrm{m}$. The ripple wavelengths of the Ag film/VHB 4910, Ag film/PDMS $1: 10$ and Ag film/PDMS $1: 10$ are $34.6 \pm 2.3,10.6 \pm 1.4$ and $8.8 \pm 10 \mu \mathrm{m}$, respectively.

8. Measurements of the deflections by dynamical laser focusing

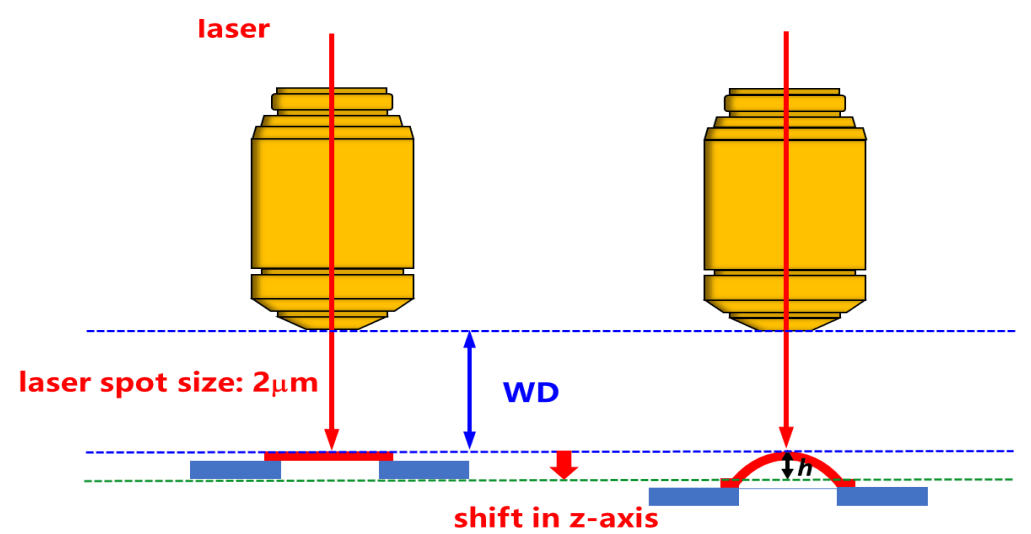

Figure S8. A schematic showing the set-up of deflection measurements based on dynamical laser focusing. An objective (SLMPlan N 50×, Olympus) with a numerical aperture (NA) of 0.35 was used to focus a collimated beam of super-continuum laser on the surface of the sample and collect the reflected light. In this configuration, the deflection of the diaphragm is determined to be equal to the shift of the microscope stage in the $z$-axis. 


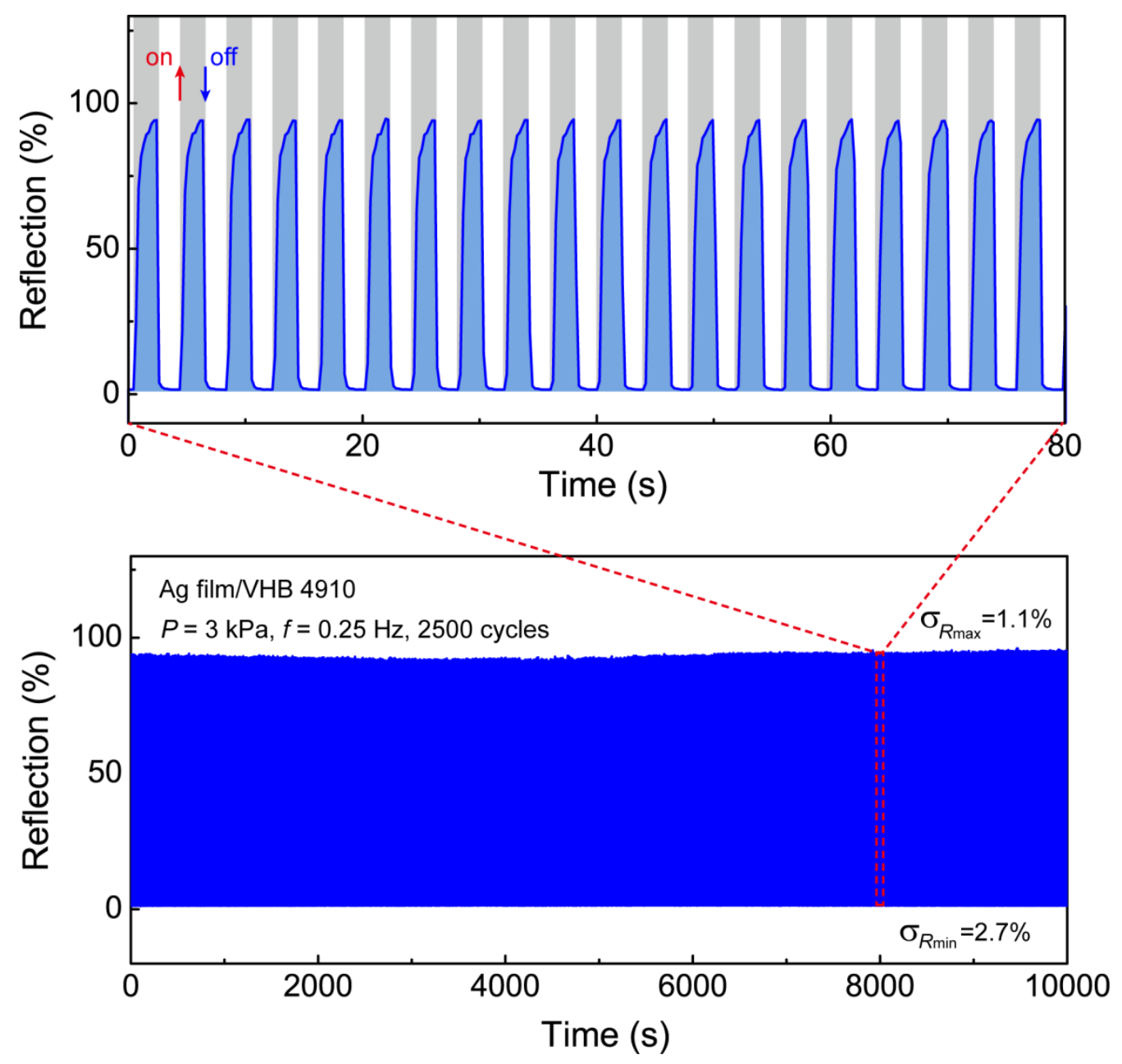

Figure S9. Cycle stability test for an Ag film/VHB 4910 broadband gas pressure sensor over 2500 cycles. In this experiment, the applied square waveform pressure was switched between 0 and $3 \mathrm{kPa}$ at a frequency of $0.25 \mathrm{~Hz}$. The reflections were monitored at the wavelength of $700 \mathrm{~nm}$. The standard deviations for the reflection maxima and minima were determined to be $1.1 \%$ and $2.7 \%$, respectively. To see clearly the realtime reflection response of the device in each cycle, we extracted the data of 20 cycles from the bottom figure, as shown in the top figure. 
10. Effect of gas pressure on the response and recovery times of broadband gas pressure sensors.

(a)

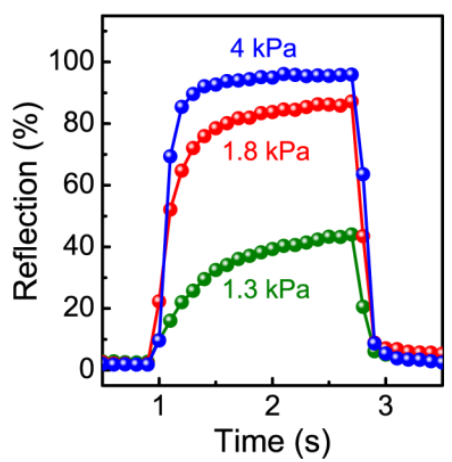

(b)

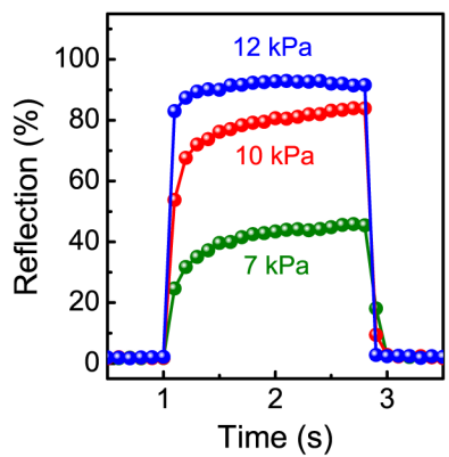

(c) $\quad$ PDMS $_{1: 8}$

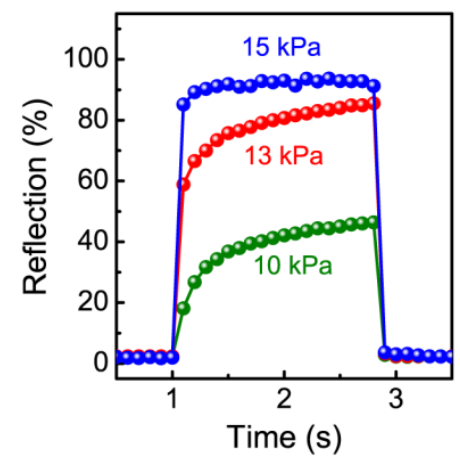

Figure S10. Response and recovery times of broadband gas pressure sensors when

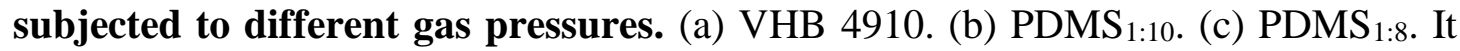
reveals that for these three sensors, their responses all tend to be rapid with increasing gas pressures. The achieved shortest response/recovery times are $\sim 200 \mathrm{~ms} /<200 \mathrm{~ms}$, $\sim 100 \mathrm{~ms} /<100 \mathrm{~ms}$ and $\sim 100 \mathrm{~ms} /<100 \mathrm{~ms}$ for VHB 4910, PDMS $1: 10$ and PDMS $_{1: 8}$, respectively. 
11. Effect of operating frequency on the performance of broadband gas pressure sensors.

(a)

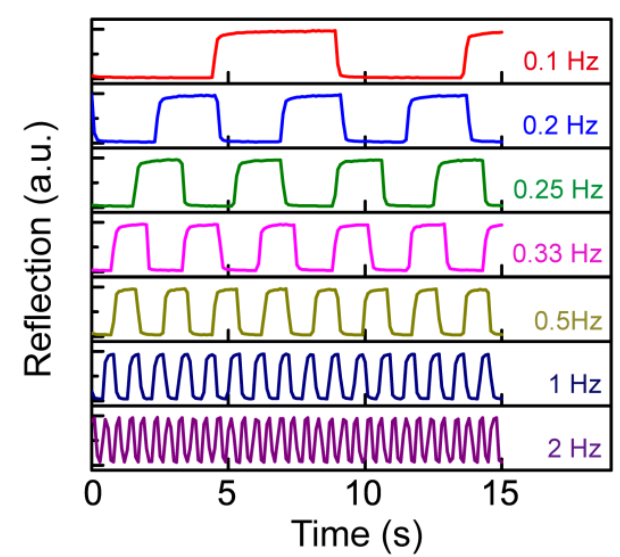

(c)

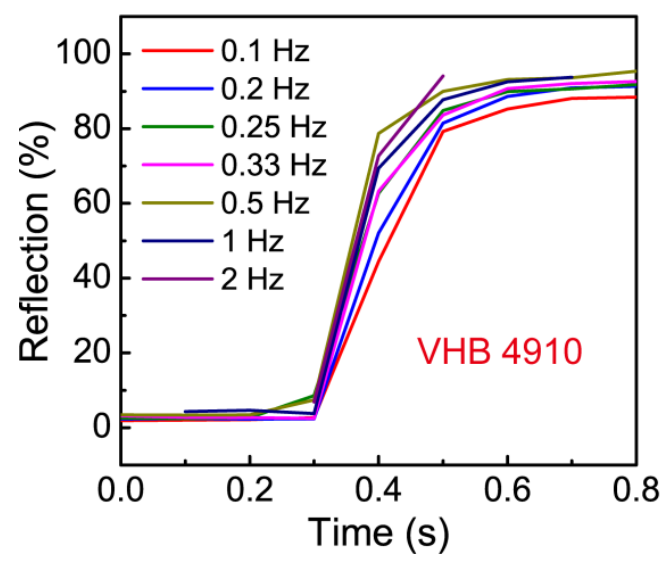

(b)

$\mathrm{PDMS}_{1: 8}$

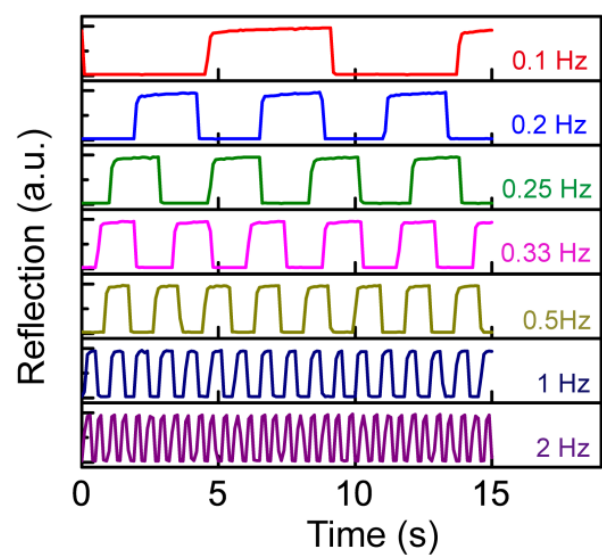

(d)

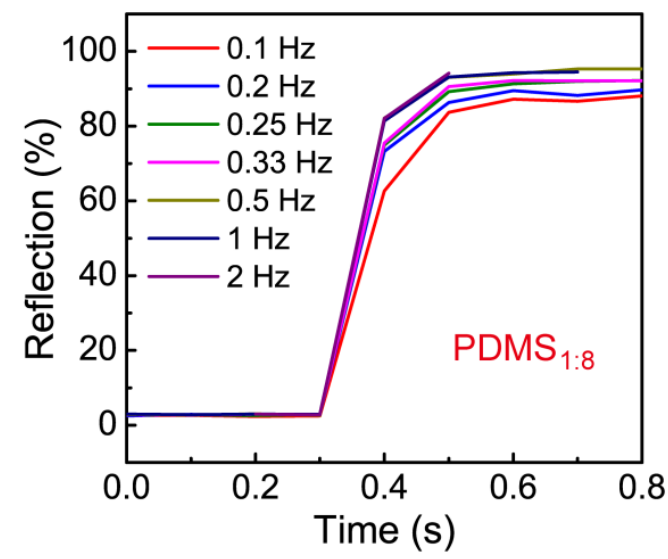

Figure S11. Effect of operating frequency on the performance of broadband gas pressure sensors. (a,b) Real-time reflection responses of an Ag film/VHB 4910 and $\mathrm{Ag}$ film/PDMS $1: 8$ to the gas pressure under different operating frequencies from 0.1-2 $\mathrm{Hz}$, respectively. (c,d) Real-time reflection responses of the Ag film/VHB 4910 and Ag film/PDMS $1: 8$ in a pressurization/depressurization cycle, respectively. 


\section{Calculations on the curvature and strain of the inflated convex mirror.}

If the surface of the inflated convex mirror was approximately considered to be parabolic, the curvature $\rho$ of the convex mirror at the apex can be written as

$$
\rho=\frac{2 h}{r^{2}}
$$

where $h$ and $r$ denote the deflection and radius of the circular membrane, respectively. According to Equation S1, we plotted the relationship between the curvatures of the convex mirror at the apex and applied pressures, as shown in Figure $6 \mathrm{~b}$.

In addition, in a cross-section cutting through the center of the convex mirror, the arc length of the convex mirror can be given as

$$
s=\frac{r^{2}}{4 h}[2 \theta+\sinh (2 \theta)]
$$

where $\theta$ is the parameter angle which is defined as

$$
\theta=\sinh ^{-1} \frac{2 h}{r}
$$

Here, we define the average radical strain on the convex mirror under pneumatic inflation as

$$
\varepsilon=\frac{s-2 r}{2 r}
$$

Thus the strain can be finally expressed as

$$
\varepsilon=\frac{r}{8 h}[2 \theta+\sinh (2 \theta)]-1
$$


13. Dependences of the average strains and spectral shifts of an Au nanogroove/PDMS array on the applied gas pressure, respectively.

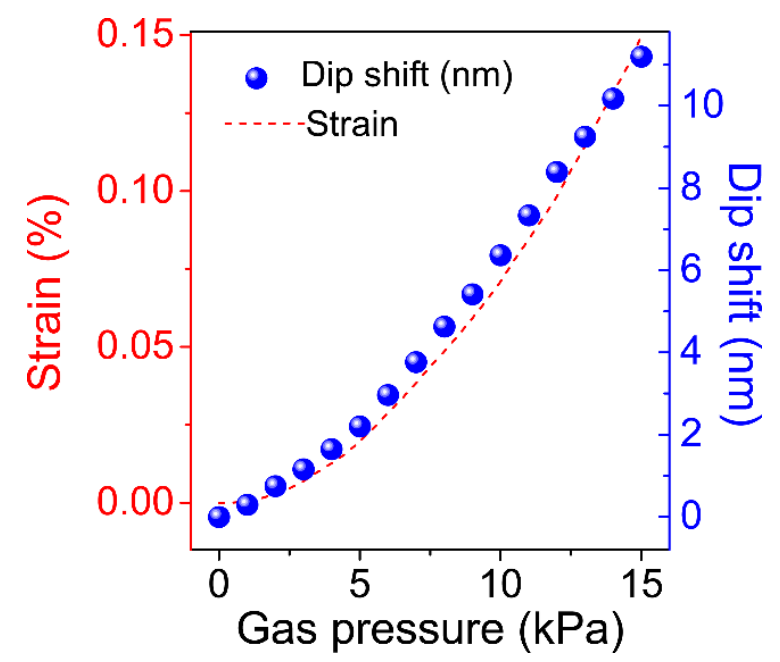

Figure S12. Dependences of the average strains (red dashed curve) and spectral shifts (blue solid dots) on the applied gas pressures, respectively. The two curves are in good agreement, suggesting that the spectral shift of the Au/PDMS nanogroove array is determined by its strain. 
14. Cycle stability of a GPNA-based plasmonic gas pressure sensor.

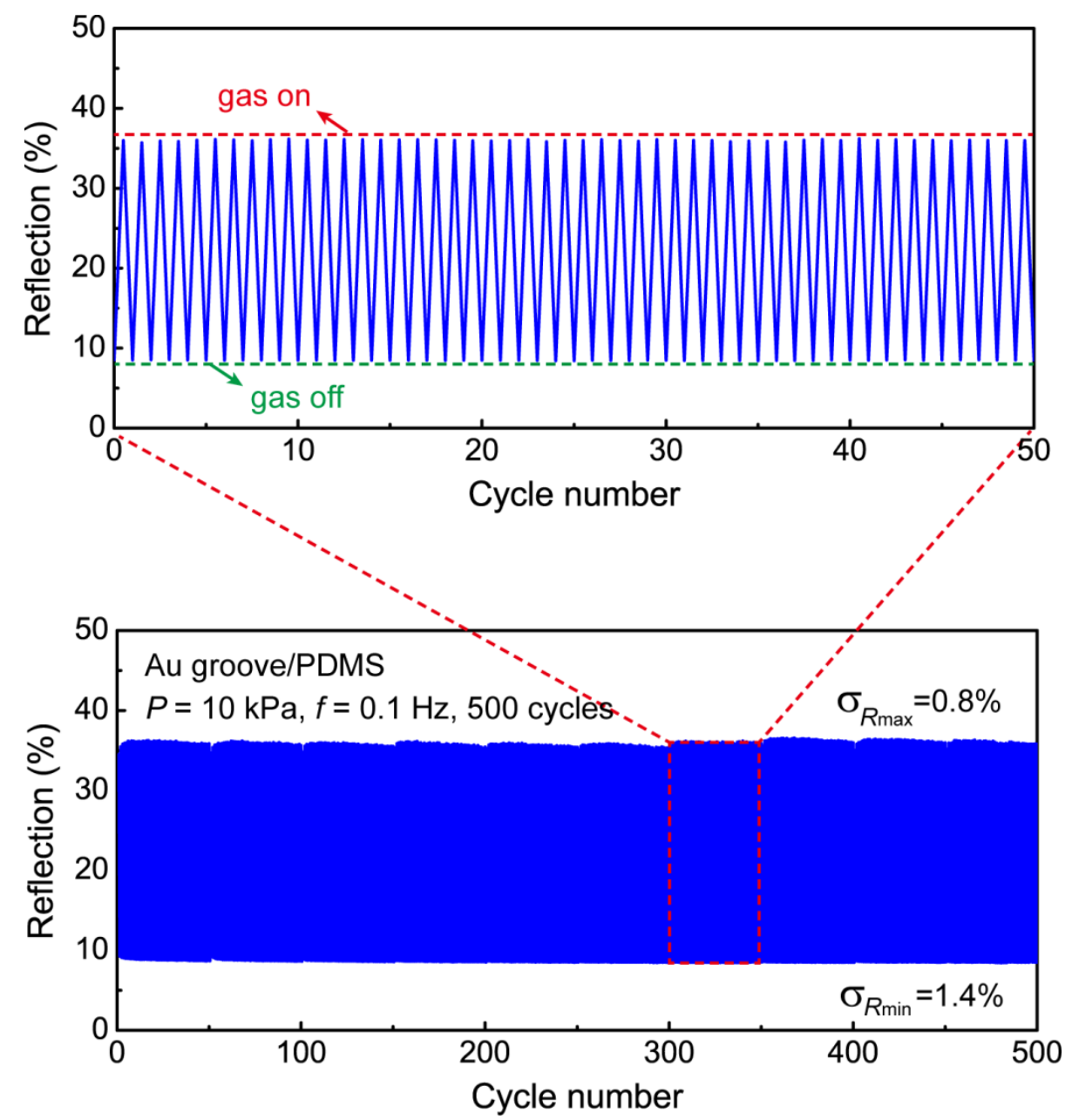

Figure S13. Cycle stability test for a GPNA-based plasmonic gas pressure sensor over 500 cycles. In this experiment, the applied square-waveform pressure was switched between 0 and $10 \mathrm{kPa}$ with a frequency of $0.1 \mathrm{~Hz}$. The reflections were monitored at the wavelength of $646 \mathrm{~nm}$. The standard deviations for the reflection maxima and minima were determined to be $0.8 \%$ and $1.4 \%$, respectively. To see clearly the real-time reflection response of the device in each cycle, we extracted the data of 50 cycles from the bottom figure, as shown in the top figure. 


\section{Estimation of energy consumption associated with pneumatic actuation}

We used established literature protocols ${ }^{1}$ to estimate the energy consumption through calculating the necessary pneumatic energy $E$ to inflate the wrinkled film to a convex mirror. As an example, we performed the calculation for the representative device in Figure 3, which was actuated with a square-waveform gas pressure at a frequency of $0.5 \mathrm{~Hz}$ (minima of $0 \mathrm{kPa}$ and maxima of $4 \mathrm{kPa}$ ). For a compressor, the minimal work needed to compress air from pressure level $P_{\text {atm }}$ to $P_{\text {load }}$ can be calculated by the integral of the pressure with the change in volume (assuming isothermal conditions and the air to behave as a perfect gas) as follow:

$$
\mathrm{W}_{\text {isotherm }}=n R T \ln \frac{P_{\text {load }}}{P_{\text {atm }}}=P_{\text {load }} V_{\text {load }} \ln \frac{P_{\text {load }}}{P_{\text {atm }}}
$$

where $n$ represents the number of moles of the total air mass flowing through the compressor, $R$ is the dry air gas constant, $T$ is the temperature of the atmosphere. $P_{\text {atm }}$ and $P_{\text {load }}$ are the absolute atmosphere pressure and loaded compressed air on the device. $V_{\text {load }}$ is the volume of the loaded compressed air. In our calculations, the absolute atmospheric pressure $P_{\text {atm }}$ and loading pressure $P_{\text {load }}$ were set as $105 \mathrm{kPa}$ and $101 \mathrm{kPa}$, respectively. The volume of the loaded compressed air can be written as

$$
V_{\text {load }}=V_{\text {pipe }}+V_{\text {chamber }}+V_{\text {channel }}
$$

where $V_{\text {pipe, }}, V_{\text {chamber }}$ and $V_{\text {channel }}$ refer to the volumes of the intake pipe, central circular chamber and channel of the gas injection system. In our configuration, $V_{\text {pipe }}, V_{\text {chamber }}$ and $V_{\text {channel }}$ are around 251,157 and $20 \mathrm{~mm}^{3}$, respectively, and hence the $V_{\text {load }}$ is around $428 \mathrm{~mm}^{3}$. According to Equation S6 and S7, the minimal energy and corresponding energy density needed to compress air from pressure level $P_{\text {atm }}$ to $P_{\text {load }}$ can be determined to be $1.7 \times 10^{-3} \mathrm{~J}$ and $22 \mathrm{~J} / \mathrm{m}^{2}$ for this device. 


\section{Movie S1}

A real-time video showing the pneumatic actuation of a modulator with an $\mathrm{Ag}$ film/VHB 4910 elastomer bilayer due to the application of a square waveform pressure (minima of $0 \mathrm{kV}$ and maxima of $4 \mathrm{kV}$ ) at a frequency of $1 \mathrm{~Hz}$.

\section{Movie S2}

A real-time video showing an application of dynamic display for a device with an Ag film/VHB 4910 elastomer bilayer when applying a square waveform pressure (minima of $0 \mathrm{kV}$ and maxima of $4 \mathrm{kV}$ ) at a frequency of $0.25 \mathrm{~Hz}$. 
Table S1. Comparison on the key capabilities for various dynamic reflecting systems

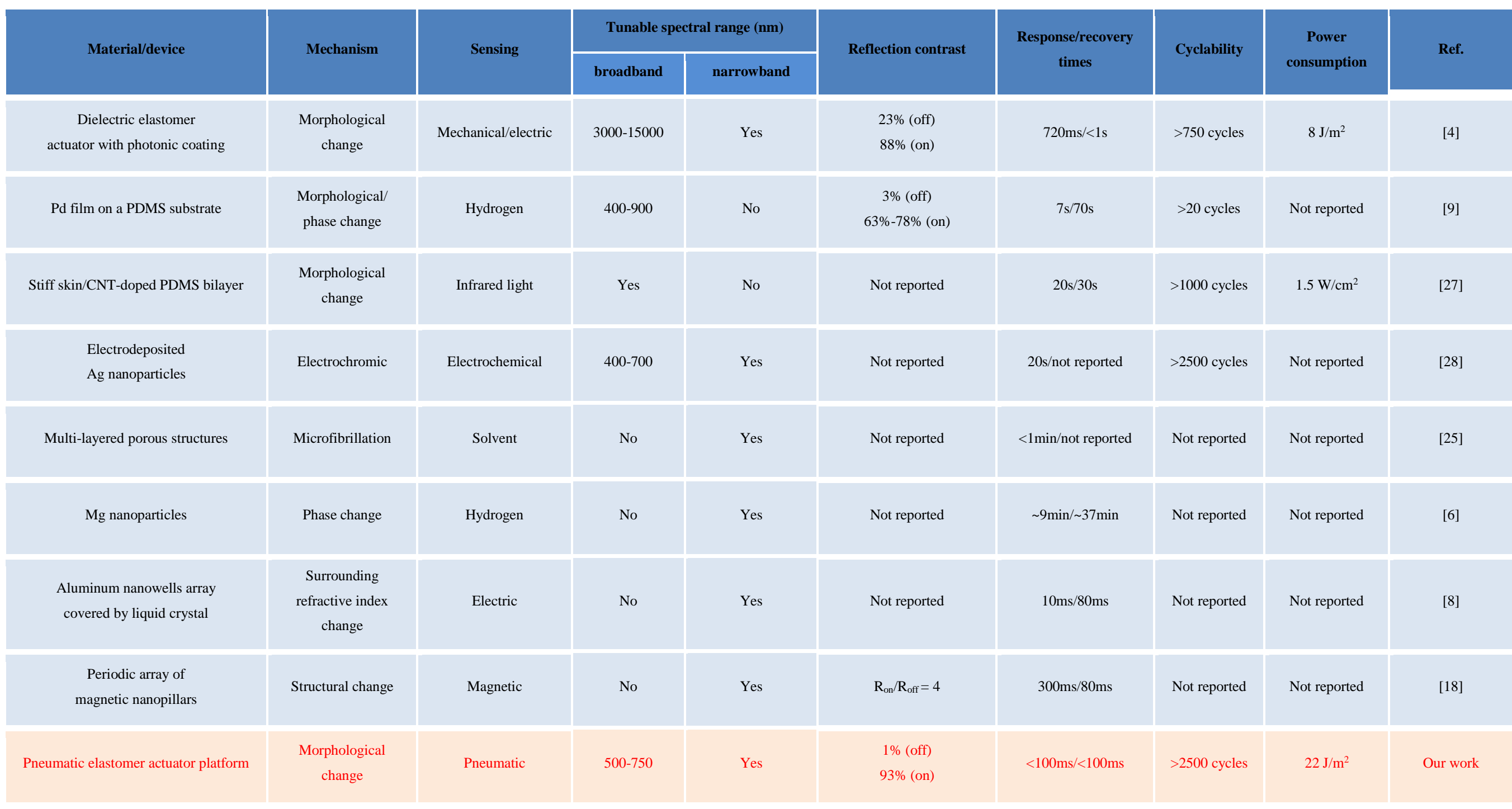


Table S2. Summary of the key capabilities for recently reported art-of-state pressure sensors

\begin{tabular}{|c|c|c|c|c|c|c|c|}
\hline Material/device & Mechanism & $\begin{array}{l}\text { Transduction } \\
\text { parameter }\end{array}$ & Sensitivity & $\begin{array}{l}\text { Limit of } \\
\text { Detection }\end{array}$ & $\begin{array}{l}\text { Response/recovery } \\
\text { times }\end{array}$ & Cyclability & Ref. \\
\hline \multirow{3}{*}{ fiber-tip with silica diaphragm } & \multirow{3}{*}{$\begin{array}{l}\text { Fabry-Pérot } \\
\text { interferometer }\end{array}$} & Wavelength & $0.34 \mathrm{~nm} \mathrm{kPa}^{-1}$ & \multirow{3}{*}{ Not reported } & \multirow{3}{*}{ Not reported } & \multirow{3}{*}{ Not reported } & \multirow{3}{*}{ [39] } \\
\hline & & Cavity length & $12.2 \mathrm{~nm} \mathrm{kPa}^{-1}$ & & & & \\
\hline & & Intensity & $\sim 0.024 \mathrm{kPa}^{-1}$ & & & & \\
\hline \multirow{2}{*}{$\begin{array}{l}\text { In-fiber cavity with hollow-core } \\
\text { photonic bandgap fiber }\end{array}$} & \multirow{2}{*}{$\begin{array}{l}\text { Fabry-Pérot } \\
\text { interferometer }\end{array}$} & Wavelength & $4.1 \times 10^{-3} \mathrm{~nm} \mathrm{kPa}^{-1}$ & \multirow{2}{*}{$2.4 \mathrm{kPa}$} & \multirow{2}{*}{ Not reported } & \multirow{2}{*}{ Not reported } & \multirow{2}{*}{ [40] } \\
\hline & & Intensity & $\sim 0.11 \mathrm{kPa}^{-1}$ & & & & \\
\hline \multirow{2}{*}{ fiber-tip with silica diaphragm } & \multirow{2}{*}{$\begin{array}{l}\text { Fabry-Pérot } \\
\text { interferometer }\end{array}$} & Wavelength & $4.2 \times 10^{-3} \mathrm{~nm} \mathrm{kPa}^{-1}$ & \multirow{2}{*}{$4.8 \mathrm{kPa}$} & \multirow{2}{*}{ Not reported } & \multirow{2}{*}{ Not reported } & \multirow{2}{*}{ [41] } \\
\hline & & Intensity & $\sim 0.11 \mathrm{kPa}^{-1}$ & & & & \\
\hline $\begin{array}{l}\text { fiber-tip with metal/polymer composite } \\
\text { diaphragm }\end{array}$ & $\begin{array}{l}\text { Fabry-Pérot } \\
\text { interferometer }\end{array}$ & Cavity length & $12.2 \mathrm{~nm} \mathrm{kPa}^{-1}$ & Not reported & Not reported & Not reported & [42] \\
\hline fiber-tip with Ag diaphragm & $\begin{array}{l}\text { Fabry-Pérot } \\
\text { interferometer }\end{array}$ & Cavity length & $70.5 \mathrm{~nm} \mathrm{kPa}^{-1}$ & Not reported & Not reported & Not reported & [43] \\
\hline fiber-tip with graphene diaphragm & $\begin{array}{l}\text { Fabry-Pérot } \\
\text { interferometer }\end{array}$ & Cavity length & $39.4 \mathrm{~nm} \mathrm{kPa}^{-1}$ & Not reported & $20 \mathrm{~min} / 20 \mathrm{~min}$ & Not reported & [44] \\
\hline
\end{tabular}




\begin{tabular}{|c|c|c|c|c|c|c|c|}
\hline fiber-tip with $\mathrm{MoS}_{2}$ diaphragm & $\begin{array}{l}\text { Fabry-Pérot } \\
\text { interferometer }\end{array}$ & Cavity length & $8.93 \times 10^{4} \mathrm{~nm} \mathrm{kPa}^{-1}$ & Not reported & Not reported & Not reported & [45] \\
\hline \multirow{2}{*}{$\begin{array}{l}\text { Twin-core fiber between } \\
\text { two single-mode fibers }\end{array}$} & \multirow{2}{*}{$\begin{array}{l}\text { Mach-Zehnder } \\
\text { interferometer }\end{array}$} & Wavelength & $9.6 \times 10^{-3} \mathrm{~nm} \mathrm{kPa}^{-1}$ & \multirow{2}{*}{$5.2 \mathrm{kPa}$} & \multirow{2}{*}{ Not reported } & \multirow{2}{*}{ Not reported } & \multirow{2}{*}{ [46] } \\
\hline & & intensity & $\sim 0.007 \mathrm{kPa}^{-1}$ & & & & \\
\hline \multirow{3}{*}{ Metal/elastomer bilayer } & \multirow{3}{*}{$\begin{array}{c}\text { Pneumatic-optical } \\
\text { transduction }\end{array}$} & Light intensity & $178 \mathrm{kPa}^{-1}$ & $1.1 \mathrm{kPa}$ & $200 \mathrm{~ms} /<200 \mathrm{~ms}$ & $>2500$ cycles & \multirow{3}{*}{ Our work } \\
\hline & & Deflection & $3.2 \times 10^{5} \mathrm{~nm} \mathrm{kPa}^{-1}$ & $0.02 \mathrm{kPa}$ & $200 \mathrm{~ms} /<200 \mathrm{~ms}$ & $>2500$ cycles & \\
\hline & & Wavelength & $0.92 \mathrm{~nm} \mathrm{kPa}^{-1}$ & $0.2 \mathrm{kPa}$ & $100 \mathrm{~ms} /<100 \mathrm{~ms}$ & $>500$ cycles & \\
\hline
\end{tabular}

\section{REFERENCES}

1. Vanderborght, B.; Verrelst, B.; Van Ham, R.; Van Damme, M.; Duran, B. M. Y.; Beyl, P. Exploiting natural dynamics to reduce energy consumption by controlling the compliance of soft actuators. Int. J. Rob. Res. 2006, 25, 343-358. 